\title{
EDITORIAL
}

\section{Summer Issue 2015}

DOI:http://dx.doi.org/10.5770/cgj.18.202

Hello! The editorial board of the Canadian Geriatrics Journal would like to introduce our second issue of 2015. In this issue we present the abstracts from the recent Technology Evaluation in the Elderly Network meeting in Toronto. This group is part of the Canadian Networks of Centres of Excellence (NCE) program, whose mandate is to develop, rigorously evaluate, and ethically disseminate information about the use of technologies for the care of seriously ill elderly patients and their families.

In addition to the abstracts of the TEEN meeting, we also have a number of original research articles. Dr. Soham Rej and colleagues ${ }^{(1)}$ attempt to examine, with an observational study, the various psychosocial risk factors that are associated with cognitive decline in patients with late life depression. Dr. Laura Middleton ${ }^{(2)}$ examines through a survey methodology barriers to referring patients with minimal cognitive impairment for cardiac rehabilitation. In a similar vein, Dr. Saad Shakeel ${ }^{(3)}$ presents a meta-analysis identifying the feasibility of physical activity programs for patients admitted to long-term care, and Dr. Jeannette Prorok et al. ${ }^{(4)}$ evaluate the effectiveness of a dementia education program for family medicine residents. Dr. Sanjeev Khanagar and colleagues ${ }^{(5)}$ performed a cross-sectional examination of the oral hygiene status of older adults in long-term care in India. We also would like to present an invited commentary on a structured approach to managing disagreements in a health-care setting, by Dr. Kenneth Rockwood. ${ }^{(6)}$

Have a great summer!

\section{REFERENCES}

1. Rej S, Begley AE, Gildengers A, et al. Psychosocial risk factors for cognitive decline in late-life depression: findings from the MTLD-III Study. Can Geriatr J. 2015;18(2) 43-50.

2. Middleton LE. Is cardiac rehabilitation exercise feasible for people with mild cognitive impairment? Can Geriatr J. 2015;18(2) 65-72.

3. Shakeel S. Identifying feasible physical activity programs for long-term care homes in the Ontario context. Can Geriatr J. 2015;18(2) 73-104.

4. Prorok JC. Evaluation of a dementia education program for family medicine residents. Can Geriatr J. 2015;18(2) 57-64.

5. Khanagar S, Naganandini S, Rajanna V, et al. Oral hygiene status of institutionalised dependent elderly in India - a crosssectional survey. Can Geriatr J. 2015;18(2) 51-56.

6. Rockwood K. I have something interesting to talk to you about: speaking to disagree, agreeably. Can Geriatr J. 2015;18(2) 105-107.
Ken Madden

Editor-in-Chief

Mark Rapoport

Associate Editor

Colleen Maxwell

Associate Editor

Canadian Geriatrics Journal 